\title{
Retrospective HRMS Screening and Dedicated Target Analysis Reveal a Wide Exposure to Pyrrolizidine Alkaloids in Small Streams
}

\author{
Barbara F. Günthardt, Felix E. Wettstein, Juliane Hollender, Heinz Singer, Jana Härri, Martin Scheringer, \\ Konrad Hungerbühler, and Thomas D. Bucheli*
}

Cite This: Environ. Sci. Technol. 2021, 55, 1036-1044

Read Online

ACCESS

山ll Metrics \& More

Article Recommendations

Supporting Information

ABSTRACT: Pyrrolizidine alkaloids (PAs) are found to be toxic pollutants emitted into the environment by numerous plant species, resulting in contamination. In this article, we investigate the occurrence of PAs in the aquatic environment of small Swiss streams combining two different approaches. Pyrrolizidine alkaloids (PAs) are toxic secondary metabolites produced by numerous plant species. Although they were classified as persistent and mobile and found to be emitted into the environment, their occurrence in surface waters is largely unknown. Therefore, we performed a retrospective data analysis of two extensive HRMS campaigns each covering five small streams in Switzerland over the growing season. All sites were contaminated with up to 12

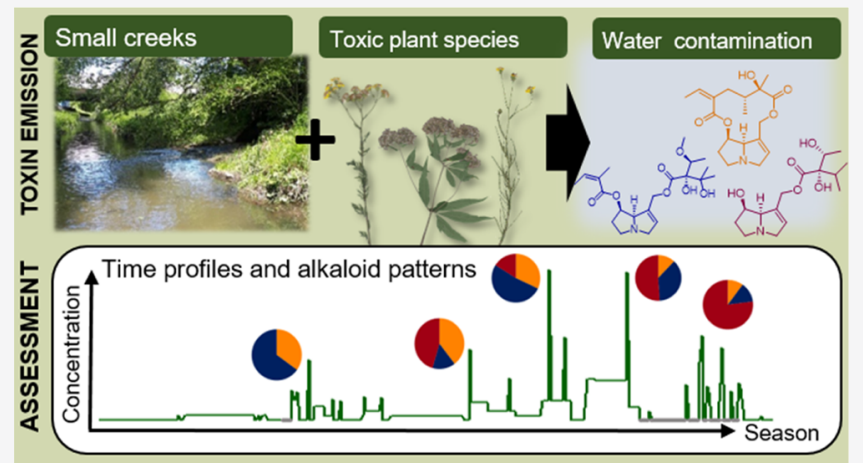
individual PAs and temporal detection frequencies between 36 and 87\%. Individual PAs were in the low $\mathrm{ng} / \mathrm{L}$ range, but rain-induced maximal total PA concentrations reached almost $100 \mathrm{ng} / \mathrm{L}$ in late spring and summer. Through PA patterns in water and plants, several species were tentatively identified as the source of contamination, with Senecio spp. and Echium vulgare being the most important. Additionally, two streams were monitored, and PAs were quantified with a newly developed, faster, and more sensitive LC-MS/MS method to distinguish different plant-based and indirect human PA sources. A distinctly different PA fingerprint in aqueous plant extracts pointed to invasive Senecio inaequidens as the main source of the surface water contamination at these sites. Results indicate that PA loads may increase if invasive species are sufficiently abundant.

\section{INTRODUCTION}

The occurrence of bioactive anthropogenic compounds in surface waters has increasingly been investigated in the last years because of their critical impact on human and environmental health. ${ }^{1-3}$ In contrast, phytotoxins have, with few exceptions, not been considered, although they are produced by a wide range of plant species, and many of them are sufficiently persistent and mobile to reach the aquatic environment. ${ }^{4,5}$ Among them, pyrrolizidine alkaloids (PAs) were recently detected in a small creek with total PA concentrations of over $125 \mathrm{ng} / \mathrm{L},{ }^{6}$ and even higher aqueous PA concentrations, with over $500 \mu \mathrm{g} / \mathrm{L}$, were quantified next to high ragwort and butterbur abundances in Denmark. ${ }^{7-9}$

In total, several hundred different PAs are known, which are composed of a largely similar necine base that forms a monoester, open-chain diester, or cyclic diester (Figure 1). ${ }^{10-12}$ The necine base exists either as tertiary amine or as corresponding $\mathrm{N}$-oxide (PANO). Because of its higher water solubility, the latter prevails as a storage and transportation form in planta. ${ }^{13}$ Approximately $3 \%$ of all flowering plants are estimated to produce PAs belonging mainly to three plant families: Asteraceae (tribes Senecioneae and Eupatorieae),
Boraginaceae, and Fabaceaea. ${ }^{14}$ While the distribution and frequency of PA-producing plants vary within biogeographical regions and land uses, the overall high number and abundance of such plant species suggest a ubiquitous presence of PAs in European agro-ecosystems. ${ }^{15,16}$ For some plant species, for example, Senecio jacobaea (common ragwort) or the invasive Senecio inaequidens (South African ragwort), even a spatial expansion has been observed in Middle Europe. ${ }^{17,18}$ So far, the consumption of contaminated tea, honey, and herbal or pollenbased supplements is the identified main route for human exposure, resulting in concern for food safety. ${ }^{19-21}$ Particularly, the 1,2-unsaturated PAs (Figure 1) are critical because they can lead to liver damage (hepatotoxicity) or cancer (genotoxic carcinogens)..$^{10,22}$

Received: September 23, 2020

Revised: December 8, 2020

Accepted: December 17, 2020

Published: December 29, 2020 
<smiles>CC(C)[C@H](O)[C@H](O)C(=O)OCC1=CCN2CCC[C@H]12</smiles>

Intermedine retronecine-based PA monoester

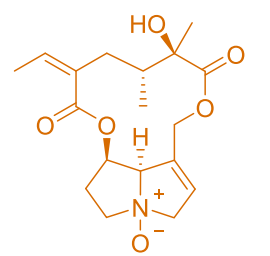

Senecionine $\mathbf{N}$-oxide retronecine-based $\mathrm{PANO}$ cyclic

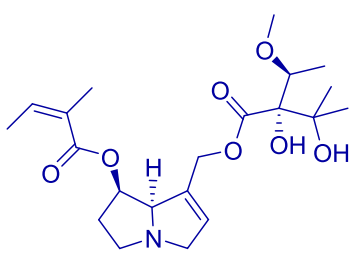

Echimidine retronecine-based PA diester

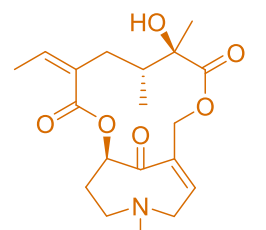

Senkirkine

otonecine-based PA cyclic
Figure 1. Exemplary structures of the most produced PAs in the study area (Switzerland) grouped according to chemical structures (necine base and esterification): intermedine-type in dark red, echimidine-type in blue, and senecionine-type in orange. Senkirkine is assigned to the senecionine-type because it is produced by the same plant species. All retronecine-based $\mathrm{PAs}$ also appear as $\mathrm{N}$-oxides (PANO), as exemplarily shown for senecionine $\mathrm{N}$-oxide. The structures of all investigated $\mathrm{PAs}$ are provided in the Supporting Information (Figure S1).
Most of the analytical methods available for the quantification of PAs in food and plant matrixes apply liquid chromatography (LC) coupled to electrospray ionization (ESI) mass spectrometry (MS). ${ }^{23}$ However, so far, only one method was described to measure PAs in surface water employing a time-consuming offline solid phase extraction (SPE). ${ }^{7}$ Besides traditional MS/ MS instruments, the newer high-resolution mass spectrometry (HRMS) detection techniques offer additional possibilities: based on exact mass traces $(m / z)$, acquired with high mass resolution $\left[\geq 20^{\prime} 000(\mathrm{~m} / z / \Delta \mathrm{m} / z)\right]$ and accuracy $(<5 \mathrm{ppm})$, measured samples can be screened even retrospectively for new compounds of interest. ${ }^{24,25}$ The reassessment of HRMS data archives was recently shown to perform well and offers a good possibility for cost-efficient exposure information, ${ }^{26,27}$ especially in light of the many extensive surface water monitoring campaigns that emerged in the last years using LC-ESIHRMS. 2,28,29 These methods are also expected to detect PAs at low concentration levels because PAs have physicochemical properties similar to those of routinely investigated anthropogenic pollutants ${ }^{4,5}$ and are well detectable with LC-ESI-MSbased methods. ${ }^{7,23}$ Therefore, retrospective screening of these big data archives represents a promising approach for a PA exposure assessment.

In this study, we comprehensively investigated the occurrence of PAs in small Swiss streams combining two different approaches for quantitative determination of 26 common PAs. In the first part, we assessed the general PA occurrence through a retrospective HRMS screening, followed by confirmation and

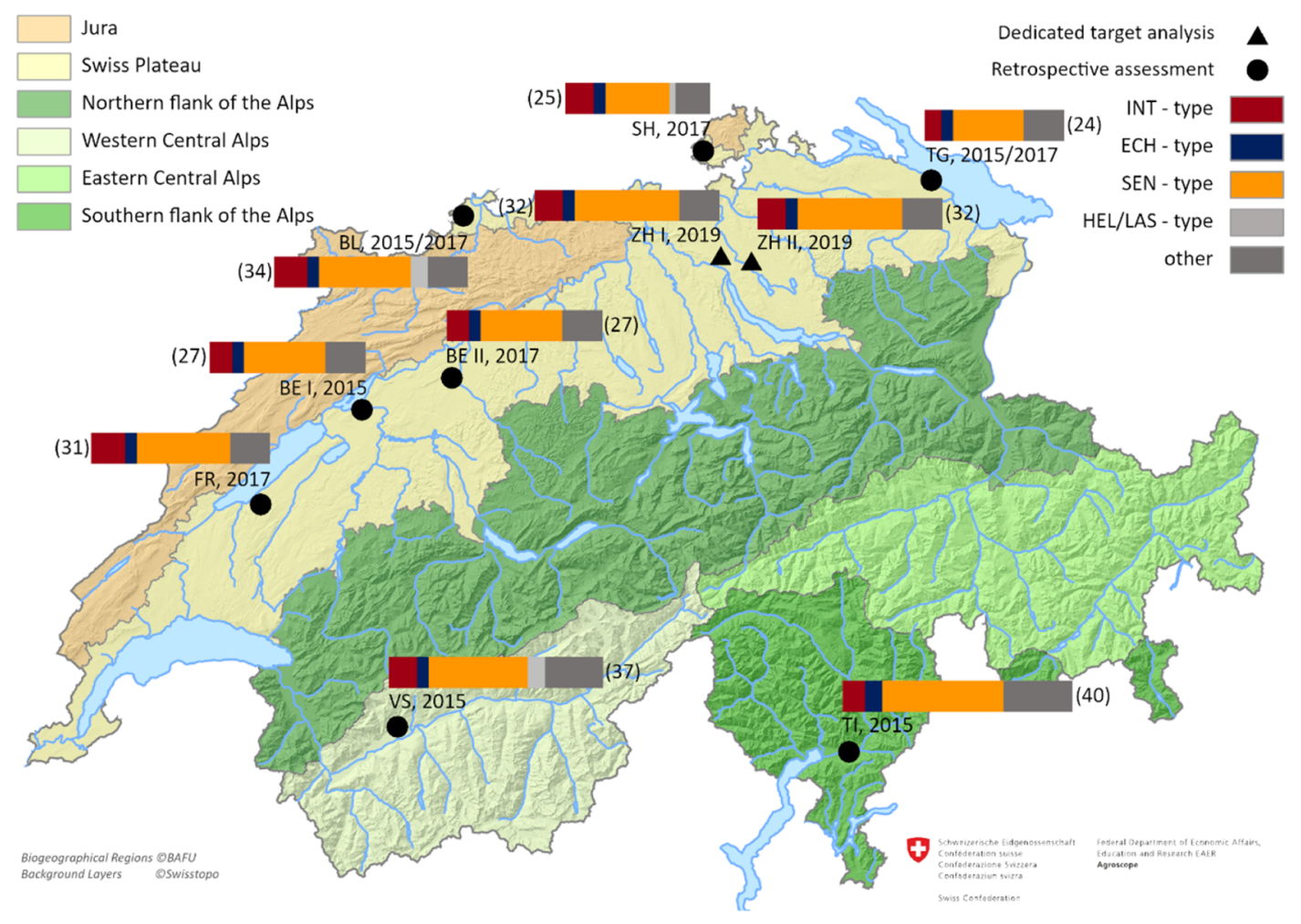

Figure 2. Locations of all sampled sites covering the small streams monitored in the retrospective screening (black circles) or the dedicated target analysis (black triangles), labeled with site abbreviation and year of monitoring. The background shows the different biogeographical regions in Switzerland. The bars indicate the presence of all PA-producing plant species (total number given in parenthesis), differentiated by PA-type: intermedine (INT, dark red), echimidine (ECH, blue), senecionine (SEN, orange), heliotrine, and lasiocarpine (HEL, LAS, light gray), and not analyzed PAs (other, dark gray). The distribution is based on Table S2 adding up the different PA-types. For more details on the sites see Supporting Information (Table S1). Source of biogeographical regions: Swiss Federal Office for the Environment ${ }^{51}$ and source of background layers: Swiss Federal Office of Topography. ${ }^{52}$ 
quantitation measurements. Data archives of two sampling campaigns in mostly agricultural catchments were selected because of the eight sites from different biogeographical regions, the high-frequent time-proportional sampling strategy, and the coverage of the growing season. ${ }^{30-32}$ The second part focused on PA source apportionment by means of specific PA fingerprints and load calculations. To this end, we developed a faster and more sensitive online SPE LC-MS/MS method for the detection of PAs in aqueous environmental samples and monitored two small creeks over the growing season, both containing the invasive $S$. inaequidens in the catchment and one receiving effluents from a wastewater treatment plant (WWTP). We hypothesize that the invasively growing $S$. inaequidens was the main PA source in these catchments manifested in a correspondingly altered PA pattern.

\section{METHODS}

HRMS Screening Campaigns 2015 and 2017. Data archives from two studies of the National Surface Water Quality Monitoring Program (NAWA) Special Program (SPEZ) in 2015 and 2017 of Switzerland's Federal Office for the Environment (FOEN) were used for retrospective PA monitoring. ${ }^{30-32}$ The two sampling campaigns were initially designed to monitor pesticides in small creeks with agricultural areas dominating the catchment areas. In both studies, five small creeks were sampled, of which two were the same to assess differences between the two years (Figure 2). The catchment area sizes varied between 0.9 and $9.0 \mathrm{~km}^{2}$, and the catchments were dominated by crops (median: $48 \%$ ). Nevertheless, also forest and grassland areas had a frequency of up to 35 and $25 \%$, respectively (details are given in the Supporting Information 1.1). To minimize human input, the catchments contained neither WWTP effluents nor combined sewer overflow, and the fraction of urban areas was below $17 \%$. The sites were located in different biogeographical and climatic regions of Switzerland: not only the Swiss plateau was covered by six sites but also the Alpine regions were represented with two sites, and two sites were at the border to the Jura (Figure 2). The study in 2015 was conducted from March till August and the one in 2017 from March till mid-October. Automatic sampling devices were used for continuous samples taking half-day time-proportional composite samples in 2015 and three-and-a-half-day time proportional composite samples in 2017. Before analysis, most of the half-day samples from 2015 were further combined depending on precipitation dynamics: during rain events, the half-day samples were measured individually to capture potential high concentrations caused by discharge effects, and during low flow conditions, samples were pooled over periods of dry weather. The three-and-a-half-days samples taken in 2017 were all measured individually. Whereas peak concentrations might have been missed, the regular setup resulted in average concentrations that are more representative of chronic exposure. Finally, the data presented here consist of 555 individual samples. Further details on the two monitoring campaigns are provided in the Supporting Information (1.3) and the original publications. $^{30-32}$

Dedicated Target Campaign in 2019. The sampling campaign in 2019 focused on source allocation including human input and the invasive $S$. inaequidens. This species spreads in Switzerland via vehicles along streets, especially highways (at the border or, if existent, in the green middle strip) and also expands into surrounding areas. ${ }^{33,34}$ In some parts of Switzerland, for example, Canton of Zürich, this species is mandatory for management. Therefore, two small creeks in the Swiss plateau were monitored ( $\mathrm{ZH} \mathrm{I}$ and $\mathrm{ZH}$ II in Figure 2) that had $S$. inaequidens growing in the catchment area and additionally obtained run-off water from the highway. The site $\mathrm{ZH}$ I had input from a highway section of approximately $2.5 \mathrm{~km}$, and ZH II received storm water from a $6 \mathrm{~km}$ section. Both highway sections were partially in construction. The invasive plant was present along the highway, but not in very high densities (anymore), because the plants were fought in the previous years and also in 2019. Both catchments also contained native Senecio species, most importantly S. jacobaea. Additionally, the effluent of the WWTP Eich in Bassersdorf, cleaning the waste water of approximately 19,000 people, discharges into this creek upstream of $\mathrm{ZH} \mathrm{II.}{ }^{35}$ The catchment area sizes were 2.9 and $12.8 \mathrm{~km}^{2}$, for $\mathrm{ZH} \mathrm{I}$ and $\mathrm{ZH} \mathrm{II}$, respectively. For the load calculations, runoff volumes were estimated from six nearby streams considering the varying catchment sizes (Supporting Information 1.2). The sites were sampled continuously from Mai till December 2019 using water-level-height-proportional sampling devices equipped with a submersed sampling bottle connected to a precision valve [Göldi Präzisionsmechanik AG (Schlieren, Switzerland)] that controls the air flux and the corresponding sampling rate (details in Supporting Information 1.3). ${ }^{36}$ Clear changes in the sampling rate took place for heavy rain events; in all other cases, the sampling was timeproportional. Two samplers were installed at each site, and the measured concentrations deviated on average by approximately $20 \%$ (Supporting Information 2.1 and Figure S5). Samples were collected for four days and stored at $4{ }^{\circ} \mathrm{C}$ until analysis. In total, 109 duplicate samples were collected and analyzed. To determine the PA fingerprint of the most important Senecio spp., individual plants of both $S$. inaequidens and S. jacobaea were collected in July 2020 in the catchment area of ZH I and soaked in $500 \mathrm{~mL}$ tap water. Aliquots were taken after 1, 4, and $24 \mathrm{~h}$ from previously shaken bottles (Supporting Information 1.10).

PA-Producing Plant Species and Substance Selection. The PA selection was based on the importance of the individual compounds in plants and food, the availability of reference standards, and the abundance of the PA-producing species in Switzerland. In Switzerland, at least 53 plant species (Table S2) are known to produce PAs, of which a high fraction can grow within the same area, as visualized in Figure 2. ${ }^{4,15,19}$ However, several of them had a low abundance; for others, only little information on their PA pattern was available, or the PA concentration is known to be low. A special focus was placed on Senecio spp. because their toxins (SEN-type PAs) were already confirmed in surface water. ${ }^{6,7}$ SEN-type PA-producing plant species are most important (Figure 2), and S. inaequidens grows invasively. Details on the plant species, the specific toxins they produce, and their relative relevance at the sampled sites are given in Figure 2, Table S2, and Figure S2. We finally selected the following list of 26 PAs sorted according to their type; heliotrine-type PAs (heliotridine-based, monoester): heliotrine (HEL), heliotrine $\mathrm{N}$-oxide (HELNO), europine (EUR), europine $\mathrm{N}$-oxide (EURNO); intermedine-type PAs (retronecine-based, monoester): intermedine (INT), intermedine $\mathrm{N}$ oxide (INTNO), lycopsamine (LYC), lycopsamine N-oxide (LYCNO); lasiocarpine-type PAs (heliotridine-based, diester): lasiocarpine (LAS), lasiocarpine $\mathrm{N}$-oxide (LASNO); echimidine-type PAs (retronecine-based, diester): echimidine (ECH), echimidine N-oxide (ECHNO); senecionine-type PAs (cyclic, 12-ring): senecionine (SEN), senecionine N-oxide (SENNO), erucifoline (ERU), erucifoline $\mathrm{N}$-oxide (ERUNO), jacobine 
Table 1. Overview on the PA Exposure of All Investigated Small Streams in the Retrospective Screening (2015 and 2017$)$ or the Dedicated Target Analysis (2019)

\begin{tabular}{|c|c|c|c|c|c|c|}
\hline site & year & $\begin{array}{l}\% \text { time with } \\
\text { detects }^{a}\end{array}$ & $\begin{array}{l}\text { maximal total PA-conc. } \\
{[\mathrm{ng} / \mathrm{L}]}\end{array}$ & $\begin{array}{c}\text { average total PA-Conc. } \\
{[\mathrm{ng} / \mathrm{L}]^{b}}\end{array}$ & $\begin{array}{c}\text { maximal number of detected } \\
\text { PAs }^{c}\end{array}$ & $\begin{array}{c}\text { median number of detected } \\
\text { PAs }{ }^{b}\end{array}$ \\
\hline $\mathrm{BL}$ & 2015 & $50 \%$ & 80 & 13 & 9 & 3 \\
\hline TG & 2015 & $45 \%$ & 98 & 9 & 5 & 2 \\
\hline BE I & 2015 & $36 \%$ & 9 & 3 & 3 & 1 \\
\hline TI & 2015 & $57 \%$ & 95 & 21 & 11 & 5 \\
\hline VS & 2015 & $68 \%$ & 92 & 18 & 12 & 4 \\
\hline $\mathrm{BL}$ & 2017 & $87 \%$ & 69 & 16 & 9 & 5 \\
\hline TG & 2017 & $76 \%$ & 44 & 8 & 5 & 3 \\
\hline BE II & 2017 & $57 \%$ & 12 & 4 & 4 & 1 \\
\hline $\mathrm{SH}$ & 2017 & $70 \%$ & 33 & 7 & 7 & 2 \\
\hline FR & 2017 & $69 \%$ & 23 & 8 & 8 & 3 \\
\hline $\mathrm{ZH} \mathrm{I}$ & 2019 & $92 \%(80 \%)^{d}$ & 67 & $14(17)^{d}$ & $11(10)^{d}$ & $4(4)^{d}$ \\
\hline $\mathrm{ZH} \mathrm{II}$ & 2019 & $100 \%(87 \%)^{d}$ & 134 & $28(31)^{d}$ & $10(9)^{d}$ & $6(4)^{d}$ \\
\hline
\end{tabular}

${ }^{a}$ On average 58 samples were analyzed per site, ranging between 34 and $71 .{ }^{b}$ Only considering samples with detects. ${ }^{c}$ In total 26 PAs are considered (including the PA N-Oxides). ${ }^{a}$ Applying the LODs of the screening method for better comparison between the monitoring campaigns.

(JAC), jacobine N-oxide (JACNO), retrorsine (RET), retrorsine N-oxide (RETNO), seneciphylline (SEP), seneciphylline $\mathrm{N}$-oxide (SEPNO), senecivernine (SEV), senecivernine $\mathrm{N}$ oxide (SEVNO), senkirkine (SEK); and the special case monocrotaline (MON, retronecine-based, cyclic, 11-ring). Examples are shown in Figure 1, and all structures are included in Figure S1.

Retrospective Data Analysis of HRMS Screening Campaigns. The samples of the campaigns 2015 and 2017 were measured previously ${ }^{30-32}$ using an online SPE-LCHRMS/MS screening method described in more detail in the Supporting Information (1.8). ${ }^{37}$ In the retrospective analysis, peaks were identified in extracted ion chromatograms, retention times were correlated within different measurement series, isotopic patterns were controlled, and, if available, MS/MS measurements were evaluated manually. The analytical identification is shown for SEPNO and the two stereoisomers INTNO and LYCNO in the Supporting Information (Figures S7 and S8). From the campaign in 2015, no water samples were left, which led to a lower confirmation level of detected PAs without MS/MS measurements. From the second campaign, for each of the five sites, the five samples with highest summed area were remeasured, specifically including data-dependent MS/MS of the PAs. Additionally, a calibration curve in tap water was prepared for an external quantification and determination of limits of detection (LODs) and limits of quantification (LOQs) in tap water. The LOD and LOQ in tap water were calculated using the signal-to-noise-ratio at $0.5 \mathrm{ng} / \mathrm{L}$, and the LODs and LOQs in the creek matrix were derived from those correcting for the correspondingly higher noise of the matrix background for each PA. This resulted for the creek matrix in a LOD median of $1.1 \mathrm{ng} / \mathrm{L}$ ranging from 0.4 to $1.6 \mathrm{ng} / \mathrm{L}$ and an LOQ median of $3.5 \mathrm{ng} / \mathrm{L}$ lying between 1.5 and $5.4 \mathrm{ng} / \mathrm{L}$ (all values are listed in Table S4). To quantify signals in matrix, the external calibration in tap water was used, and correspondingly ion enhancement or suppression by the creek water matrix was not considered, which led to increased uncertainties in quantification. More details on the process and compound identification are given in the Supporting Information (2.2).

Dedicated PA Target Analysis Using LC-MS/MS. For the analysis of the samples from 2019, a faster and more sensitive method was developed and optimized specifically for the PAs, which is also based on an online SPE LC-MS/MS approach. In brief, samples were filtered, enriched with online SPE using a $\mathrm{C}_{18}$ reversed phase, chromatographically separated within $13.75 \mathrm{~min}$ on a Kinetex $\mathrm{XB}-\mathrm{C}_{18}$ column with an acidic water-methanol gradient, and finally detected in multiple reaction monitoring (MRM) mode on an ABSciex QTRAP 5500 MS (Vaughan, Canada). The separation including three MRMs is visualized for ECHNO and the two isomers SEVNO and SENNO in the Supporting Information (Figures S3 and S4). The LC-MS/MS method was fully validated and yielded the following parameters: Linearity was shown between 0.25 and $200 \mathrm{ng} / \mathrm{L}$. The LOD ranged between 0.07 and $0.7 \mathrm{ng} / \mathrm{L}$ (median $0.3 \mathrm{ng} / \mathrm{L}$ ) for the $\mathrm{ZH}$ I creek matrix and between 0.1 and $0.7 \mathrm{ng} / \mathrm{L}$ (median $0.4 \mathrm{ng} / \mathrm{L}$ ) for ZH II. Correspondingly, the LOQ lied between 0.2 and $2.3 \mathrm{ng} / \mathrm{L}$ (median $1.1 \mathrm{ng} / \mathrm{L}$ ) and 0.4 and $2.3 \mathrm{ng} / \mathrm{L}$ (median $1.3 \mathrm{ng} / \mathrm{L}$ ), for ZH I and II, respectively. Therefore, the optimized method was approximately by a factor three more sensitive than the HRMS screening method, even with a much lower sample volume $(2 \mathrm{~mL}$ vs $20 \mathrm{~mL})$. The instrument precision (in nanopure and creek water) was always below $4 \%$, and the method precision was with three exceptions below $6 \%$ indicating a stable measurement. Also, the SPE recoveries were satisfying (e.g., absolute SPE recovery median at $25 \mathrm{ng} / \mathrm{L}$ was $69 \%$ and relative SPE recovery median at $25 \mathrm{ng} / \mathrm{L}$ was $105 \%$ ). Stronger variations were possible for the matrix effect $( \pm 48 \%)$, but the median was below $20 \%$. However, calibrations were prepared in the matrix (with correction for background concentrations) compensating for these variations. Details on the method, parameter determination, and parameters for each compound are described in the Supporting Information (1.9, 2.3 , and 2.4).

\section{RESULTS AND DISCUSSION}

General Pyrrolizidine Alkaloid Occurrence. The occurrence of PAs in stream water samples was confirmed at all ten investigated sites including the retrospective screening and the dedicated target analysis. Although all sites showed a PA contamination, the number of detected PAs, the detection frequency, and the total concentration strongly varied (Table 1). The maximal number of detected PAs ranged from three up to twelve for the site in the Western Central Alps (VS). The two sites in the canton of Bern had the lowest number of detected PAs with three (BE I) and four (BE II). The median number of detected PAs was for all sites on average only slightly above three 
showing that the PA contamination was dominated by few PAs. In total, the occurrence of 16 different PAs in Swiss stream water was confirmed. Detection frequencies were at least $36 \%$ of the time (BE I) increasing up to a permanent PA contamination over the whole sampling period ( $\mathrm{ZH} \mathrm{II}$ ) pointing to a frequent presence of PA in small streams. The two sites from the dedicated target analysis showed the highest frequencies, which implies an increased contamination. However, this is also due to the lower sensitivity of the analytical method used in the retrospective monitoring, possibly indicating higher exposures at concentrations below the LOD. The site $\mathrm{ZH}$ II was showing the highest maximal total PA concentration with $134 \mathrm{ng} / \mathrm{L}$, but also the sites VS, TI, and TG in 2015 showed high maximal concentrations with 92,95 , and $98 \mathrm{ng} / \mathrm{L}$, respectively. The lowest concentrations were detected for the two sites in the canton of Bern with only maximum values of $9 \mathrm{ng} / \mathrm{L}$ (BE I) and $12 \mathrm{ng} / \mathrm{L}$ (BE II). The average total PA concentration ranged from only 3 to $28 \mathrm{ng} / \mathrm{L}$, indicating a contamination in the low ng/L-range for most of the time.

Spatial Patterns in the Retrospective Monitoring and Plant Species Occurrences. The occurrence of different PAtypes in stream water can be assessed in light of their detection frequencies and concentration patterns. In stream water, SENtype-PAs occurred most widely, namely, at all sites, followed by ECH-type-PAs occurring at $70 \%$ of the sites (Table S9). In contrast, INT-type-PAs were less important (detected only at three sites), and HEL-type-PAs, LAS-type-PAs, and MON-typePAs were not detected at all. Figure 3 shows the average

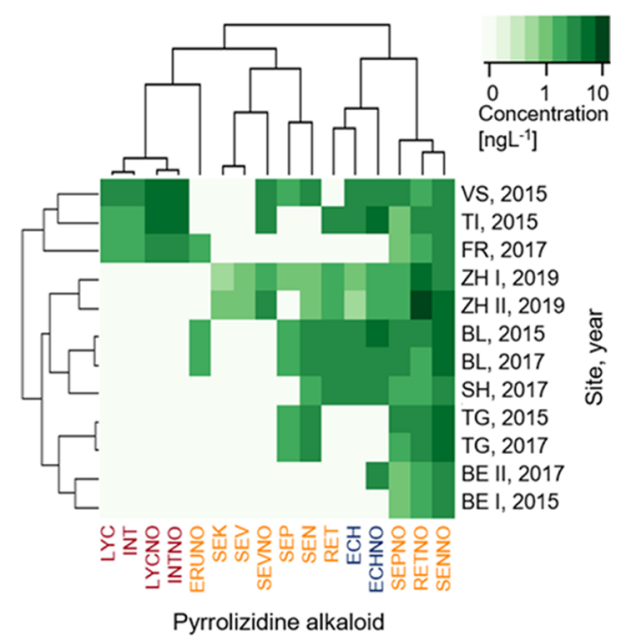

Figure 3. PA patterns for all investigated surface water monitoring sites (BL and TG were monitored in two seasons) based on the logarithmic average concentration of each PA. Only detected PAs are included, and the PA color classifies the toxins into intermedine-type (INT, dark red), echimidine-type (ECH, blue), and senecionine-type (SEN, orange) (for chemical structures, see Figure 1). The heatmap with dendrograms was created in $\mathrm{R}$ (Version 4.0.0) using the heatmap function.

concentrations for each detected PA and site, clearly demonstrating the dominance of SEN-type- and ECH-typePAs. The average concentrations of the main toxins ( $\mathrm{N}$-oxides) were in the same order of magnitude: INTNO between 3.4 and $6.7 \mathrm{ng} / \mathrm{L}, \mathrm{ECHNO}$ between 1.9 and $8.2 \mathrm{ng} / \mathrm{L}$, and SENNO between 2.7 and $6.7 \mathrm{ng} / \mathrm{L}$. Generally, the $\mathrm{N}$-oxides were more dominant, that is, higher concentrated (Figures 3 and S9a) and detected more often (Figure S9b), than the corresponding tertiary amines, which is consistent with their prevalence in the plants itself and their higher water solubility and thus leaching potential. The summed concentrations were usually higher for SEN-type-PAs, but this was essentially determined by the number of available reference standards (INT-type: 4, ECHtype: 2, SEN-type: 13).

The water exposure to the different PA-types can further be evaluated in relation to the prevailing plants and their corresponding major PA-types as the likely input source. The most dominating plant species were Senecio spp. (totally 18) and/or Petasites spp. (in total three), both producing the major SEN-type-PAs and having a broad distribution in Switzerland (Figure 2 and Table S2), as well as Echium vulgare, producing ECH-type-PAs. The more scattered occurrence of ERUNO, SEVNO, SEV, and SEK can again be attributed to different Senecio or Petasites spp. resulting in different toxin patterns (Figure 3). However, unknown patterns in the individual plant species and different chemotypes make it impossible to establish a causal relationship between PA detection in creek water and their presence in specific species. ${ }^{38}$ Although several plant species produce INT-type-PAs, these toxins were detected at few sites only. This might have several reasons: lower concentrations in the plants, different leaching behavior, more infrequent plant growth, or most probably lower abundance of these plant species in agriculturally dominated areas. E. vulgare and different Senecio spp. are weed and ruderal plants that can grow along roads, fields, or even creeks, and their presence in agricultural areas is expected.

Literature Comparison of Pyrrolizidine Alkaloid Contamination. Currently, no detailed surface water monitoring investigating PAs is available, and therefore, no in-depth comparison with literature data can be made. However, leaching of JAC and SEN from S. jacobaea hotspots led to concentrations above $500 \mu \mathrm{g} / \mathrm{L}$ each in Danish surface waters. ${ }^{7,8}$ Hama et al. detected various PA patterns not necessarily overlapping in the plant and water matrices. Nevertheless, their results support the proposed plant sources and the frequent detection of SEN/ SENNO in our study. Additionally, SEN-type-PAs were already detected at one identical site ( $\mathrm{ZH} \mathrm{I}$ ) in a pilot screening in $2018 .^{6}$ The concentrations in the one grab sample were higher compared with the data presented, but the PA pattern was very similar.

Because of the importance of PAs for food safety, detailed studies on the occurrence of PAs in Swiss honey and plant pollen are available. ${ }^{12,21}$ In these matrixes, the same three PA-types were detected, which point to the same sources. However, the relative importance of the different PA-types varied. Whereas we found SEN-type-PAs most frequently, followed by ECH-typePAs and finally INT-type-PAs, Kast et al. suggested E. vulgare as most important plant species for bee product contaminations followed by Eupatorium cannabinum (producing INT-type-PAs) and finally Senecio spp. ${ }^{12}$ Different years and sites of investigations and, more importantly, completely different exposure pathways might explain these differences. Interestingly, honeys from the Alpine region contained PAs more frequently, which the authors explain by the floristic distribution pattern. ${ }^{21}$ The same might be the reason for the high toxin numbers in the stream water of the two Alpine creeks (VS and TI). Unfortunately, plant species reported to occur only in these regions produce rare PAs that were not included in this study (e.g., Myosotis decumbens, see Table S2).

Temporal Occurrence. Stream water monitoring of PAs over several months provided first-time insights on the influence of biotic (i.e., vegetation and biomass production) and abiotic 
factors (i.e., hydrodynamics driven by precipitation) on their occurrence dynamics at different temporal scales. The development of the PA concentration over the growing season is exemplarily visualized for the site VS in Figure 4 (all sites are

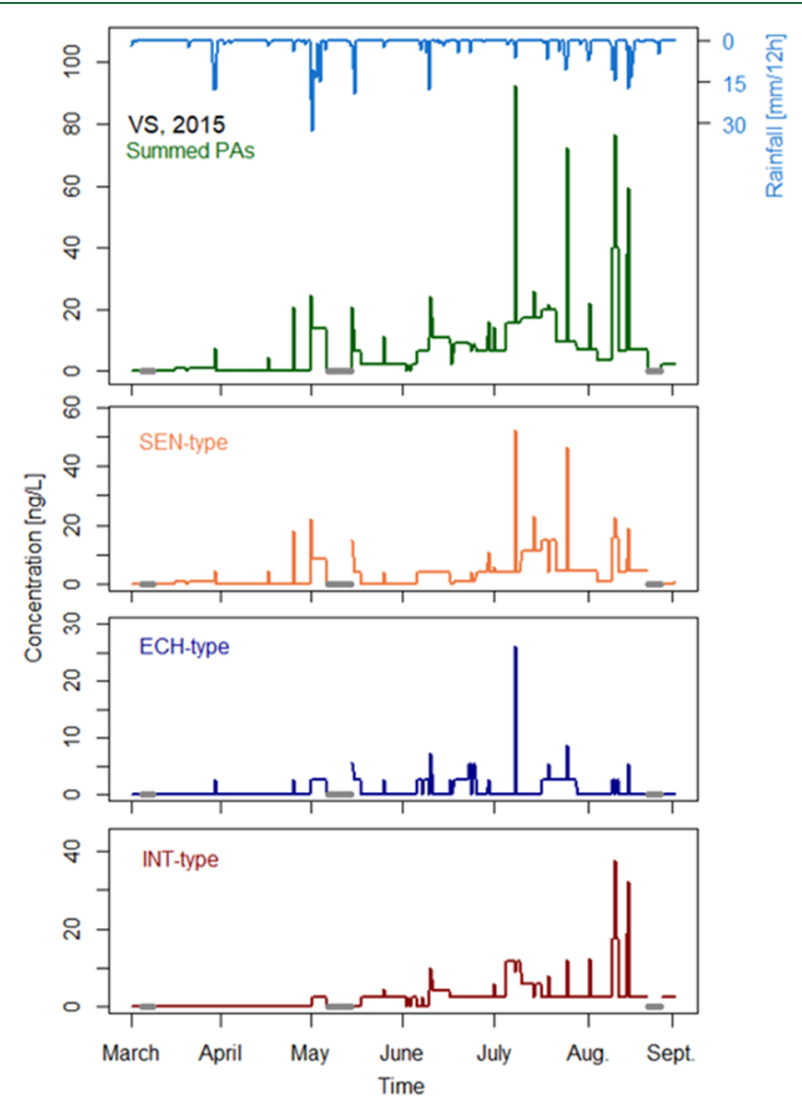

Figure 4. PA occurrence in the small stream at the site VS, from March to September 2015, ${ }^{30,31}$ including the sums of total PA, senecionine (SEN)-, echimidine (ECH)-, and intermedine (INT)-type concentrations (for structures, see Figure 1). Thick gray lines indicate periods of interrupted sampling. Source of rain data: MeteoSwiss. ${ }^{53}$

shown in Figure S10). Before April, almost no PAs were detected, basically because the plants as the presumed major source do not grow early in the year. Afterward, the concentrations started to increase over spring until maximal concentrations were, with one exception (BL, 2017), reached between June and September. In a comparison of the different PA-types, INT-type-PAs showed a tendency for later occurrence in the season (VS in Figure 4, TI and FR in Figure S10). For ECH-type- and SEN-type-Pas, no differences can be seen. As PA-producing plants are most likely the major emission source, it is instructive to consult the literature on PA concentrations in Senecio spp. plants over the growth period (no data available for other species). Total PA concentrations are mostly reported to remain on the same order of magnitude over the season until they decrease in autumn, sometimes with increased concentrations in the sprouts early in the season or increasing concentrations over the season. ${ }^{8,39-41}$ Because of the increasing biomass, the absolute PA amount in the plants also increases over the season until it reaches a maximum once plants have fully matured. Among the different plant parts, the highest concentrations are often detected in the flower heads in summer. ${ }^{39,42,43}$ In light of this general temporal dynamic, increasing PA concentrations in the stream water over the vegetation period with maximum in summer to early autumn appears plausible. E. cannabinum, possibly the plant mainly responsible for the occurrence of INT-type-PAs, has a later blooming period (starting in July), which might explain the delayed occurrence of these toxins in surface water. The discussed seasonal trends seem to occur regularly as confirmed through the intraannual comparison of TG and BL, both monitored in 2015 and 2017 (Supporting Information 2.7).

The seasonal PA occurrence at relatively low concentrations is superimposed by individual peak concentrations that seem to be triggered by rain events, as shown in Figure 4. Therefore, a primary rain-driven transport from the PAs either directly from the plants or from possible soil reservoirs into the creeks is most likely. ${ }^{44,45}$ Comparing these results with the pesticide data of the same monitoring studies discloses not only similarities but also differences. ${ }^{30-32}$ The main difference is the temporal development over the season, which is due to the different sources of the contamination (continuously growing plant species vs defined incidences of pesticide application). For example, the rain event at the site VS in Mid of May caused highest pesticide, but relatively low PA concentrations, whereas precipitation in
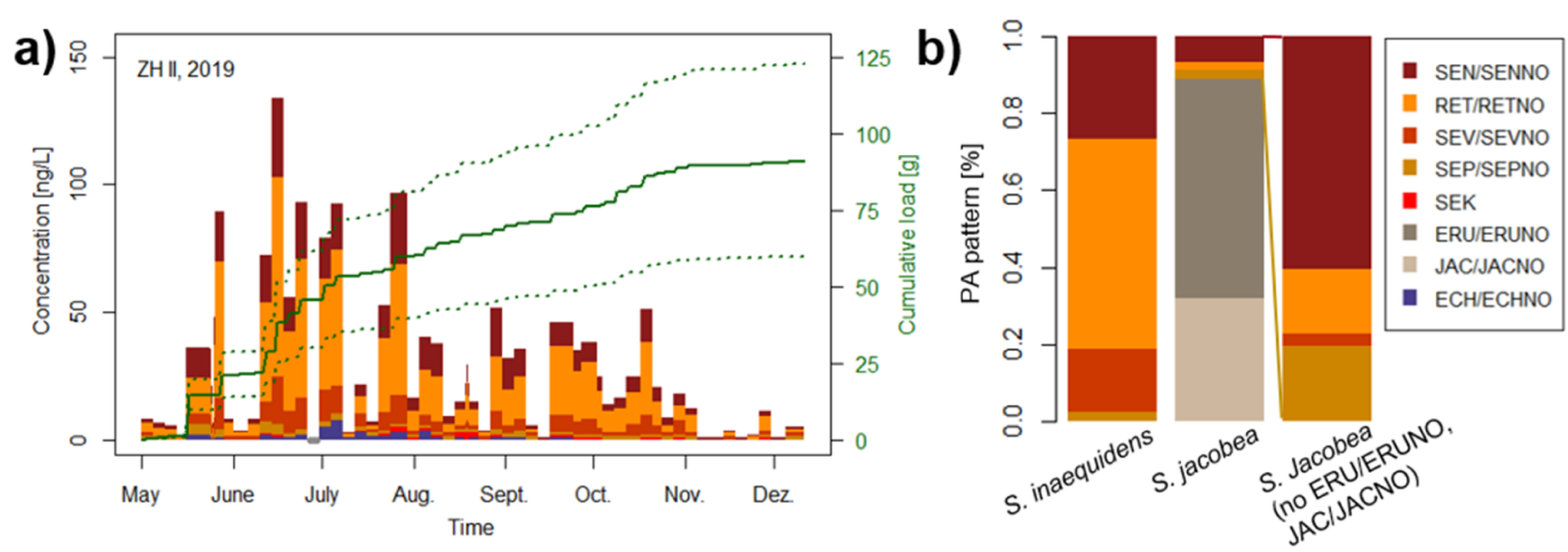

Figure 5. (a) Occurrence of the different PAs at the site ZH II in the stream water over the season 2019. The cumulative load of all PAs is shown in green with the uncertainty range indicated through the green dotted lines (for details, see Supporting Information 2.1). N-oxides are combined with the tertiary amines. (b) PA patterns in aqueous plant leachates determined for two Senecio spp. and additionally $S$. jacobaea omitting the epoxidecontaining jacobine with $\mathrm{N}$-oxide (JAC/JACNO) and erucifoline with $\mathrm{N}$-oxide (ERU/ERUNO). For full names of PA abbreviations in figure legend, see main text. 
August led to high PA and low pesticide contaminations (see Figure 4 and Doppler et al.). ${ }^{30}$ However, there were several incidences with peak concentrations of both types of micropollutants, which indicates a similar transport process based on a rain-induced runoff. A similar emission dynamics was earlier reported for estrogenic isoflavones. ${ }^{46}$

Dedicated Target Analysis Focusing on Different Sources. The dedicated target analysis was conducted to complement the retrospective data analysis with an in-depth assessment of possible sources of the most occurring SEN-typePAs. Potential contributions by human-derived emissions were evaluated through load calculations, and the exposure through the invasive $S$. inaequidens was considered over toxin patterns. Generally, the two investigated sites ( $\mathrm{ZH} \mathrm{I}$ and $\mathrm{ZH} \mathrm{II}$ ) were both dominated by SEN-type-PAs that reached maximal concentrations of 60 to $140 \mathrm{ng} / \mathrm{L}$ between June and August (Figures 5a, S10 and S11). Comparing these two sites with the sites of the retrospective analysis reveals that the site $\mathrm{ZH}$ II clearly had the highest concentrations of SEN-type-PAs (Table S9), but the concentrations of ZH I were only slightly above the mean of all sites. Nevertheless, both sites showed the highest detection frequencies, and ZH II even showed a permanent SEN-type-PA contamination (Table S9). These concentrations translate over the monitored time into total loads of $9 \mathrm{~g}$ for $\mathrm{ZH} \mathrm{I}$ and $91 \mathrm{~g}$ for ZH II. Based on these loads, a possible emission over the WWTP at $\mathrm{ZH}$ II is neglectable because the totally consumed PA in that area and the monitored time is estimated to be below $5 \mathrm{~g}$ (details in Supporting Information 2.8). However, the input via WWTP might be more relevant in winter, when no plants are growing and producing PAs.

The PA patterns of the aqueous plant leachates (Figure 5b) provide a basis for the distinction between $S$. jacobaea and the invasive $S$. inaequidens, the two most important Senecio spp. at these sites. $S$. jacobaea was dominated by ERU/ERUNO and JAC/JACNO, of which none was detected in the $\mathrm{ZH}$ water samples (and ERUNO only sporadically in the retrospective monitoring). Possibly they are less stable because both PAs contain an epoxide as functional group. When omitting these two toxins, SEN/SENNO was the most important toxins in $S$. jacobaea followed by SEP/SEPNO (Figure 5 b). In contrast, $S$. inaequidens had RET/RETNO as the main toxin, and in addition, also, SEN/SENNO and SEV/SEVNO contributed significantly to the pattern. Comparing these plant patterns with the pattern in the water samples reveals a general high impact of $S$. inaequidens through the dominant occurrence of RET/ RETNO (Figure 5a). The peaks at the end of May were partitioned approximately equally between both species (illustrated by equal SEN/SENNO and RET/RETNO or SEV/SEVNO and SEP/SEPNO concentrations in Figure 5). However, the dominance of $S$. inaequidens increased later in the season. For a long-term assessment, the plant patterns can be compared with the average concentrations in the two creeks. According to these patterns, the invasive species contributed approximately equally to $S$. jacobaea at $\mathrm{ZH}$ I but was around three times more important for the contamination of ZH II. Therefore, we conclude that the invasive $S$. inaequidens can, if present in sufficient amounts, cause an increased PA contamination.

Environmental Relevance. To evaluate the environmental relevance of the detected PA contamination, emitted loads are compared with the emission of other phytotoxins, and possible toxic effects are assessed. The loads for ZH I and II cumulated over the season to 9 and $91 \mathrm{~g}$, respectively (see Figures S11 and 5a), which in these catchments translate to approximately 30 to $70 \mathrm{mg} / \mathrm{ha} / \mathrm{y}$, assuming no significant contribution in winter. Literature data for isoflavones, which are estrogenic phytotoxins produced by red clover, showed emissions in a similar range: loads varied between 35 and $215 \mathrm{mg} / \mathrm{ha} / \mathrm{y} .{ }^{46,47}$ Interestingly, red clover is an agricultural plant accounting for around $50 \%$ of the plants in grassland fields with a much higher biomass than PAproducing species that are scattered irregularly. Because the concentrations in the plant species are similar (isoflavones: $0.05-12.5 \mathrm{mg} / \mathrm{g}_{\mathrm{dw}}{ }^{47}$ PAs: $\left.0.1-11 \mathrm{mg} / \mathrm{g}_{\mathrm{dw}}{ }^{38,39,41}\right)$, either a higher fraction of the PAs is emitted into the environment and/ or the PAs are more stable in surface water. Isoflavones have half-lives around 1 month, ${ }^{44}$ whereas the sample storage testing confirmed a PA stability at $+4{ }^{\circ} \mathrm{C}$ for at least 2 months (Supporting Information 2.3). Compared with pesticides, ${ }^{48}$ the emission of phytotoxins was lower. Potentially most critical are rain events with high concentrations that strongly impact the total emission and often correlate with pesticide peak concentrations, which might lead to increased mixture toxicity. The aquatic toxicity of the PAs itself can only be estimated because no measured effect data are available. Based on estimations from the ecological structure-activity relationships $(\mathrm{ECOSAR})^{49}$ model, no direct risk arises for aquatic organisms. Most concerning is the potential genotoxic effect of the 1,2unsaturated PAs, which are bioactivated to dehydropyrrolizidines and can already exert negative effects at low concentrations. ${ }^{10,13,22}$ Together with the broad occurrence of the PAs, their genotoxicity might pose a risk for livestock consuming surface water. A possible human health risk due to contaminated drinking water is comparably low, as the consumption of contaminated food results in a higher daily intake. ${ }^{19}$ Nevertheless, PAs were recently even found in groundwater wells, ${ }^{9}$ and the threshold of toxicological concern (TTC) for genotoxic contaminants in drinking water is $10 \mathrm{ng} / \mathrm{L},{ }^{50}$ which we frequently found to be exceeded in small streams.

\section{ASSOCIATED CONTENT}

\section{SI Supporting Information}

The Supporting Information is available free of charge at https://pubs.acs.org/doi/10.1021/acs.est.0c06411.

Details on sampling sites, load calculation, sampling devices, evaluation, PA structures and producing plant species, chemicals, standard solutions and calibrations, online SPE-LC-HRMS/MS screening method with confirmation and quantitation, online SPE-LC-MS/MS PA method, its validation and quality issues, all time profiles, comparison of 2015 and 2017, and aqueous Senecio extracts (PDF)

Concentrations of all PAs and sites (XLSX)

\section{AUTHOR INFORMATION}

\section{Corresponding Author}

Thomas D. Bucheli - Environmental Analytics, Agroscope, Zürich 8046, Switzerland; 이이.org/0000-0001-99713104; Phone: 0415846873 42; Email: thomas.bucheli@ agroscope.admin.ch

\section{Authors}

Barbara F. Günthardt - Environmental Analytics, Agroscope, Zürich 8046, Switzerland; Institute of Biogeochemistry and Pollutant Dynamics, ETH Zürich, Zürich 8092, Switzerland; () orcid.org/0000-0003-0319-5272 
Felix E. Wettstein - Environmental Analytics, Agroscope, Zürich 8046, Switzerland

Juliane Hollender - Institute of Biogeochemistry and Pollutant Dynamics, ETH Zürich, Zürich 8092, Switzerland; Eawag, Swiss Federal Institute of Aquatic Science and Technology, Dübendorf 8600, Switzerland; (1) orcid.org/0000-00024660-274X

Heinz Singer - Eawag, Swiss Federal Institute of Aquatic Science and Technology, Dübendorf 8600, Switzerland; ○ orcid.org/0000-0002-8542-3699

Jana Härri - Environmental Analytics, Agroscope, Zürich 8046, Switzerland; Institute of Biogeochemistry and Pollutant Dynamics, ETH Zürich, Zürich 8092, Switzerland

Martin Scheringer - Institute for Chemical and Bioengineering, ETH Zurich, Zürich 8093, Switzerland; RECETOX, Masaryk University, Brno 625 00, Czech Republic; $\odot$ orcid.org/00000002-0809-7826

Konrad Hungerbühler - Institute for Chemical and Bioengineering, ETH Zurich, Zürich 8093, Switzerland

Complete contact information is available at:

https://pubs.acs.org/10.1021/acs.est.0c06411

\section{Funding}

Funding of the Swiss National Science Foundation (Project "PHYtotoxins: aquatic miCROPOLLutants of concern?" (PHYCROPOLL); Grant No. 200021_162513/1) is gratefully acknowledged.

\section{Notes}

The authors declare no competing financial interest.

\section{ACKNOWLEDGMENTS}

We acknowledge the help of Simon Mangold and Nicolas Creusot with the HRMS campaigns, Otmar Zoller and Christina Kast for inputs regarding Senecio, Hans Reinhard and Jawameer Hama for comments on PA analytics, Jonas Winizki for assistance with Figure 2, and Carina D. Schönsee for sharing her PA expertise. Furthermore, we thank the Federal Office for the Environment (FOEN) for the permission to use the extensive NAWA SPEZ monitoring campaigns.

\section{REFERENCES}

(1) Schulze, S.; Zahn, D.; Montes, R.; Rodil, R.; Quintana, J. B.; Knepper, T. P.; Reemtsma, T.; Berger, U. Occurrence of emerging persistent and mobile organic contaminants in European water samples. Water Res. 2019, 153, 80-90.

(2) Schäfer, R. B.; von der Ohe, P. C.; Kühne, R.; Schüürmann, G.; Liess, M. Occurrence and Toxicity of 331 Organic Pollutants in Large Rivers of North Germany over a Decade (1994 to 2004). Environ. Sci. Technol. 2011, 45, 6167-6174.

(3) Moschet, C.; Piazzoli, A.; Singer, H.; Hollender, J. Alleviating the reference standard dilemma using a systematic exact mass suspect screening approach with liquid chromatography-high resolution mass spectrometry. Anal. Chem. 2013, 85, 10312-10320.

(4) Günthardt, B. F.; Hollender, J.; Hungerbühler, K.; Scheringer, M.; Bucheli, T. D. Comprehensive Toxic Plants-Phytotoxins Database and Its Application in Assessing Aquatic Micropollution Potential. J. Agric. Food Chem. 2018, 66, 7577-7588.

(5) Bucheli, T. D. Phytotoxins: Environmental Micropollutants of Concern? Environ. Sci. Technol. 2014, 48, 13027-13033.

(6) Günthardt, B. F.; Schönsee, C. D.; Hollender, J.; Hungerbühler, K.; Scheringer, M.; Bucheli, T. D. Is there anybody else out there? - First Insights from a Suspect Screening for Phytotoxins in Surface Water. Chimia 2020, 74, 129-135.
(7) Hama, J. R.; Strobel, B. W. Pyrrolizidine alkaloids quantified in soil and water using UPLC-MS/MS. RSC Adv. 2019, 9, 30350-30357.

(8) Hama, J. R.; Strobel, B. W. Occurrence of pyrrolizidine alkaloids in ragwort plants, soils and surface waters at the field scale in grassland. Sci. Total Environ. 2020, 755, 142822.

(9) Kisielius, V.; Hama, J. R.; Skrbic, N.; Hansen, H. C. B.; Strobel, B. W.; Rasmussen, L. H. The invasive butterbur contaminates stream and seepage water in groundwater wells with toxic pyrrolizidine alkaloids. Sci. Rep. 2020, 10, 19784.

(10) Moreira, R.; Pereira, D.; Valentão, P.; Andrade, P. Pyrrolizidine Alkaloids: Chemistry, Pharmacology, Toxicology and Food Safety. Int. J. Mol. Sci. 2018, 19, 1668.

(11) Teuscher, E.; Lindequist, U. Biogene Gifte: Biologie-ChemiePharmakologie-Toxikologie; 3rd ed.; Wissenschaftliche Verlagsgesellschaft mbH: Stuttgart, Germany, 2010.

(12) Kast, C.; Kilchenmann, V.; Reinhard, H.; Droz, B.; Lucchetti, M. A.; Dübecke, A.; Beckh, G.; Zoller, O. Chemical fingerprinting identifies Echium vulgare, Eupatorium cannabinum and Senecio spp. as plant species mainly responsible for pyrrolizidine alkaloids in beecollected pollen. Food Addit. Contam., Part A 2018, 35, 316-327.

(13) Fu, P. P.; Xia, Q.; Lin, G.; Chou, M. W. Pyrrolizidine AlkaloidsGenotoxicity, Metabolism Enzymes, Metabolic Activation, and Mechanisms. Drug Metab. Rev. 2004, 36, 1-55.

(14) Boppré, $M$. The ecological context of pyrrolizidine alkaloids in food, feed and forage: an overview. Food Addit. Contam., Part A 2011, $28,260-281$.

(15) Info Flora: The National Data and Information Center on the Swiss Flora. https://www.infoflora.ch/en/ (accessed April 16, 2020).

(16) Lucchetti, M. A.; Glauser, G.; Kilchenmann, V.; Dübecke, A.; Beckh, G.; Praz, C.; Kast, C. Pyrrolizidine Alkaloids from Echium vulgare in Honey Originate Primarily from Floral Nectar. J. Agric. Food Chem. 2016, 64, 5267-5273.

(17) Wiedenfeld, H. Plants containing pyrrolizidine alkaloids: toxicity and problems. Food Addit. Contam., Part A 2011, 28, 282-292.

(18) Flade, J.; Beschow, H.; Wensch-Dorendorf, M.; Plescher, A.; Wätjen, W. Occurrence of Nine Pyrrolizidine Alkaloids in Senecio vulgaris L. Depending on Developmental Stage and Season. Plants (Basel) 2019, 8, 54.

(19) Mulder, P. P. J.; Sánchez, P. L.; These, A.; Preiss-Weigert, A.; Castellari, M. Occurrence of Pyrrolizidine Alkaloids in food. EFSA Supporting Publications 2015, 12, 859E.

(20) Kaltner, F.; Rychlik, M.; Gareis, M.; Gottschalk, C. Occurrence and risk assessment of pyrrolizidine alkaloids in spices and culinary herbs from various geographical origins. Toxins 2020, 12, 155 .

(21) Kast, C.; Lucchetti, M. A., Pyrrolizidine alkaloids-a case study of Swiss honey. Chemical Hazards in Foods of Animal Origin, Wageningen Academic Publishers: Wageningen, Netherlands, 2019; pp 282-292.

(22) Wiedenfeld, H.; Edgar, J. Toxicity of pyrrolizidine alkaloids to humans and ruminants. Phytochem. Rev. 2011, 10, 137-151.

(23) Crews, C.; Berthiller, F.; Krska, R. Update on analytical methods for toxic pyrrolizidine alkaloids. Anal. Bioanal. Chem. 2010, 396, 327338.

(24) Schymanski, E. L.; Jeon, J.; Gulde, R.; Fenner, K.; Ruff, M.; Singer, H. P.; Hollender, J. Identifying Small Molecules via High Resolution Mass Spectrometry: Communicating Confidence. Environ. Sci. Technol. 2014, 48, 2097-2098.

(25) Hollender, J.; Schymanski, E. L.; Singer, H. P.; Ferguson, P. L. Nontarget Screening with High Resolution Mass Spectrometry in the Environment: Ready to Go? Environ. Sci. Technol. 2017, 51, 1150511512.

(26) Alygizakis, N. A.; Samanipour, S.; Hollender, J.; Ibáñez, M.; Kaserzon, S.; Kokkali, V.; van Leerdam, J. A.; Mueller, J. F.; Pijnappels, M.; Reid, M. J.; Schymanski, E. L.; Slobodnik, J.; Thomaidis, N. S.; Thomas, K. V. Exploring the Potential of a Global Emerging Contaminant Early Warning Network through the Use of Retrospective Suspect Screening with High-Resolution Mass Spectrometry. Environ. Sci. Technol. 2018, 52, 5135-5144.

(27) Creusot, N.; Casado-Martinez, C.; Chiaia-Hernandez, A.; Kiefer, K.; Ferrari, B. J. D.; Fu, Q.; Munz, N.; Stamm, C.; Tlili, A.; Hollender, J. 
Retrospective screening of high-resolution mass spectrometry archived digital samples can improve environmental risk assessment of emerging contaminants: A case study on antifungal azoles. Environ. Int. 2020, 139, 105708 .

(28) Munz, N. A.; Burdon, F. J.; de Zwart, D.; Junghans, M.; Melo, L.; Reyes, M.; Schönenberger, U.; Singer, H. P.; Spycher, B.; Hollender, J.; Stamm, C. Pesticides drive risk of micropollutants in wastewaterimpacted streams during low flow conditions. Water Res. 2017, 110, 366-377.

(29) Arp, H. P. H.; Brown, T. N.; Berger, U.; Hale, S. E. Ranking $\mathrm{REACH}$ registered neutral, ionizable and ionic organic chemicals based on their aquatic persistency and mobility. Environmental Science: Processes \& Impacts 2017, 19, 939-955.

(30) Doppler, T.; Mangold, S.; Wittmer, I.; Spycher, S.; Comte, R.; Stamm, C.; Singer, H.; Junghans, M.; Kunz, M. Hohe PSM-Belastung in Schweizer Bächen-NAWA-SPEZ-Kampagne untersucht Bäche in Gebieten intensiver Landwirtschaftlicher Nutzung. Aqua Gas 2017, 4, 46-56.

(31) Spycher, S.; Mangold, S.; Doppler, T.; Junghans, M.; Wittmer, I.; Stamm, C.; Singer, H. Pesticide Risks in Small Streams-How to Get as Close as Possible to the Stress Imposed on Aquatic Organisms. Environ. Sci. Technol. 2018, 52, 4526-4535.

(32) Spycher, S.; Teichler, R.; Vonwyl, E.; Longrée, P.; Stamm, C.; Singer, H.; Daouk, S.; Doppler, T.; Junghans, M.; Kunz, M. Anhaltend hohe PSM-Belastung in Bächen-NAWA SPEZ 2017: Kleine Gewässer in Gebieten mit intensiver Landwirtschaftlich verbreitet betroffen. Aqua Gas 2019, 4, 14-25.

(33) WWEA: Office of Waste, Water, Energy and Air: Annual Books of Discharges and Water Levels (Canton of Zürich). https://www.zh. ch/de/umwelt-tiere/umweltschutz/gebietsfremde-arten.html\#196929687 (accessed Sept. 07, 2020).

(34) Infoflora: Invasive South African Ragwort. https://www. infoflora.ch/de/assets/content/documents/neophyten/inva_sene ina_d.pdf (accessed Aug. 14, 2020).

(35) Community Bassersdorf: Waste Water Treatment Plant Eich. https://www.bassersdorf.ch/verwaltung/dienstleistungen-az/ara. html/298 (accessed Sept. 02, 2020).

(36) Schönenberger, U.; Patrick, M.; Wullschleger, S.; Stamm, C. A water-level proportional water sampler for remote areas. Zenodo $\mathbf{2 0 2 0}$, DOI: 10.5281 /zenodo.4280534.

(37) Huntscha, S.; Singer, H. P.; McArdell, C. S.; Frank, C. E.; Hollender, J. Multiresidue analysis of 88 polar organic micropollutants in ground, surface and wastewater using online mixed-bed multilayer solid-phase extraction coupled to high performance liquid chromatography-tandem mass spectrometry. J. Chromatogr. A 2012, 1268, 7483.

(38) Macel, M.; Vrieling, K.; Klinkhamer, P. G. L. Variation in pyrrolizidine alkaloid patterns of Senecio jacobaea. Phytochemistry 2004, 65, 865-873.

(39) Carvalho, S.; Macel, M.; Mulder, P. P. J.; Skidmore, A.; Van Der Putten, W. H. Chemical variation in Jacobaea vulgaris is influenced by the interaction of season and vegetation successional stage. Phytochemistry 2014, 99, 86-94.

(40) Bucheli, T. D.; Erbs, M.; Hartmann, N.; Vogelgsang, S.; Wettstein, F. E.; Forrer, H.-R. Estrogenic mycotoxins in the environment. Mitt. Lebensmittelunters. Hyg. 2005, 96, 386-403.

(41) Eller, A.; Chizzola, R. Seasonal variability in pyrrolizidine alkaloids in Senecio inaequidens from the Val Venosta (Northern Italy). Plant Biosyst. 2016, 150, 1306-1312.

(42) Hartmann, T.; Zimmer, M. Organ-specific Distribution and Accumulation of Pyrrolizidine Alkaloids during the Life History of two Annual Senecio Species. J. Plant Physiol. 1986, 122, 67-80.

(43) Wiedenfeld, H. Plants containing pyrrolizidine alkaloids: toxicity and problems. Food Addit. Contam. 2011, 28, 282-292.

(44) Nowak, M.; Wittke, C.; Lederer, I.; Klier, B.; Kleinwächter, M.; Selmar, D. Interspecific transfer of pyrrolizidine alkaloids: An unconsidered source of contaminations of phytopharmaceuticals and plant derived commodities. Food Chem. 2016, 213, 163-168.
(45) Selmar, D.; Wittke, C.; Beck-von Wolffersdorff, I.; Klier, B.; Lewerenz, L.; Kleinwächter, M.; Nowak, M. Transfer of pyrrolizidine alkaloids between living plants: A disregarded source of contaminations. Environ. Pollut. 2019, 248, 456-461.

(46) Hoerger, C. C.; Wettstein, F. E.; Hungerbühler, K.; Bucheli, T. D. Occurrence and Origin of Estrogenic Isoflavones in Swiss River Waters. Environ. Sci. Technol. 2009, 43, 6151-6157.

(47) Hoerger, C. C.; Wettstein, F. E.; Bachmann, H. J.; Hungerbühler, K.; Bucheli, T. D. Occurrence and Mass Balance of Isoflavones on an Experimental Grassland Field. Environ. Sci. Technol. 2011, 45, 67526760.

(48) Gerecke, A. C.; Schärer, M.; Singer, H. P.; Müller, S. R.; Schwarzenbach, R. P.; Sägesser, M.; Ochsenbein, U.; Popow, G. Sources of pesticides in surface waters in Switzerland: pesticide load through waste water treatment plants--current situation and reduction potential. Chemosphere 2002, 48, 307-315.

(49) Ecological Structure Activity Relationships (ECOSAR) Predictive Model, V 2.0; United States Environmental Protection Agency: Washington, DC, 2017.

(50) Mons, M. N.; Heringa, M. B.; van Genderen, J.; Puijker, L. M.; Brand, W.; van Leeuwen, C. J.; Stoks, P.; van der Hoek, J. P.; van der Kooij, D. Use of the Threshold of Toxicological Concern (TTC) approach for deriving target values for drinking water contaminants. Water Res. 2013, 47, 1666-1678.

(51) Federal Office for the Environment: Biogeographical Regions of Switzerland. https://www.bafu.admin.ch/bafu/en/home/topics/ landscape/publications-studies/publications/die-biogeographischenregionen-der-schweiz.html (accessed Sept. 14, 2020).

(52) Federal Office of Topography: Swisstopo Onlineshop. https:// shop.swisstopo.admin.ch/en/products/landscape (accessed Sept. 14, 2020).

(53) Federal Office of Meteorology and Climatology: Services and Publications. https://www.meteoswiss.admin.ch/home/services-andpublications $/$ produkte.html $=\&$ pageIndex $=0 \&$ tab $=$ search_tab (accessed Sept. 14, 2020). 